\title{
Exposure of LS-180 Cells to Drugs of Diverse Physicochemical and Therapeutic Properties Up-regulates P-glycoprotein Expression and Activity
}

\author{
Alaa H. Abuznait; Shawn G. Patrick; Amal Kaddoumi \\ Department of Basic Pharmaceutical Sciences, College of Pharmacy, University of Louisiana at Monroe, Monroe, USA.
}

Received, January 14, 2011; Revised, June 1, 2011; Accepted, June 9, 2011; Published, June 13, 2011.

\begin{abstract}
PURPOSE. Drug transporters are increasingly recognized as important determinants of variability in drug disposition and therapeutic response, both in pre-clinical and clinical stages of drug development process. The role P-glycoprotein (P-gp) plays in drug interactions via its inhibition is well established. However, much less knowledge is available about drugs effect on P-gp up-regulation. The objective of this work was to in vitro investigate and rank commonly used drugs according to their potencies to upregulate P-gp activity utilizing the same experimental conditions. METHODS. The in vitro potencies of several drugs of diverse physicochemical and therapeutic properties including rifampicin, dexamethasone, caffeine, verapamil, pentylenetetrazole, hyperforin, and $\beta$-estradiol over broad concentration range to up-regulate $\mathrm{P}$-gp expression and activity were examined. For dose-response studies, LS-180 cells were treated with different concentrations of the selected drugs followed by P-gp protein and gene expressions analyses. P-gp functionality was determined by uptake studies with rhodamine 123 as a P-gp substrate, followed by $\mathrm{E}_{\max } / \mathrm{EC}_{50}$ evaluation. RESULTS. The results demonstrated a dose-dependent increase in P-gp expression and activity following treatments. At $50 \mu \mathrm{M}$ concentration (hyperforin, $0.1 \mu \mathrm{M}$ ), examined drugs increased P-gp protein and gene expressions by up to 5.5 and 6.2-fold, respectively, while enhanced P-gp activity by 1.8-4-fold. The rank order of these drugs potencies to up-regulate P-gp activity was as following: hyperforin $>>>$ dexamethasone $\approx \beta$ estradiol $>$ caffeine $>$ rifampicin $\approx$ pentylenetetrazole $>$ verapamil. CONCLUSIONS. These drugs have the potential to be involved in drug interactions when administered with other drugs that are P-gp substrates. Further studies are needed to in vivo evaluate these drugs and verify the consequences of such induction on P-gp activity for in vitro-in vivo correlation purposes.
\end{abstract}

This article is open to POST-PUBLICATION REVIEW. Registered readers (see "For Readers") may comment by clicking on ABSTRACT on the issue's contents page.

\section{INTRODUCTION}

Pharmacokinetic interactions involving transporters have been accepted as playing an important role in the toxicity and efficacy of certain medications that are substrates to these transporters (1). Transporterbased drug interactions can be inhibitory, inductive, or both, and may involve influx or efflux transporters (2). ATP-binding cassette (ABC) efflux transporters are among the most important and highly expressed transporters inside our bodies, and they play major role in the absorption, disposition, toxicity and efficacy of diverse range of drugs (3). Even though a relatively smaller proportion of drug interactions are mediated by transporters compared to metabolizing enzymes, their importance in the disposition of drugs is increasingly recognized (4), and, in some cases, such role of transporters in drug interaction may result in serious adverse reactions especially with drugs having narrow therapeutic index such as digoxin (5).

P-glycoprotein (P-gp), the product of MDR1 $(A B C B 1)$ gene, is perhaps the best-known and most studied $A B C$ efflux transporter which, under normal physiological conditions, is widely expressed in barrier and excretory tissues (6). Because of its extensive tissue distribution and broad substrate specificity, P-gp contributes to the disposition of wide variety of drugs of different therapeutic categories.

Corresponding Author: Amal Kaddoumi, Ph.D. College of Pharmacy, University of Louisiana at Monroe, 1800 Bienville Dr., Monroe, LA, USA; E-mail: kaddoumi@ulm.edu. 
The extent to which P-gp influences pharmacokinetics and pharmacodynamics of a substrate depends on the route of administration, the therapeutic target and the physicochemical properties of the compound. For example, intestinal P-gp determines plasma concentration of the orally administered drug digoxin (7), lowering its oral bioavailability and therapeutic efficiency. In addition, the expression of P-gp in target tissues may be responsible for substrate drugs poor delivery to these tissues. For example, CNS expression of P-gp plays an important role in the brain disposition and efficacy of many pharmacological drugs. Numerous studies demonstrated P-gp can restrict brain uptake of wide variety of anticancer (8), antiepileptic and antineurodegenerative (9).

Today, the role of transporters in predicting drug-drug interactions (DDIs) is receiving much attention, and the FDA has issued a draft guidance on DDIs that recognizes their importance (10). Nonetheless, much of the work on DDIs focused on the inhibitory role of P-gp (11-13), and only few studies were devoted to explore the effect of P-gp induction on the absorption and disposition of drugs (14-16). Available in vitro data revealed that P-gp function can be induced pharmacologically; for example, dexamethasone, rifampin, and St. John's Wort are reported to enhance P-gp activity (17-19). In addition, P-gp expression at the BBB in a rat model increased by $30 \%$ following a three-day in vivo treatment with ritonavir $(20 \mathrm{mg} / \mathrm{kg})$ or dexamethasone $(80 \mathrm{mg} / \mathrm{kg})$-once daily (20). This increase in P-gp at the BBB by these drugs may potentially create problems in achieving sustained delivery of such drugs, if they are substrates for P$\mathrm{gp}$, to the CNS by increasing their efflux. Moreover, induction of P-gp by one drug could affect permeability of other P-gp substrates (21) as shown by Ghanem and colleagues who demonstrated that spironolactone $(200 \mu \mathrm{mol} / \mathrm{kg})$ induces P-gp expression following intraperitoneal administration with potential impact on intestinal absorption of digoxin (22).

As the appreciation for inductive drug interactions by transporters is increasing and is more common than previously thought, we aimed in this study, to in vitro screen and rank the inductive potencies of several drugs on P-gp expression and function. The selected drugs are highly diverse in their chemical structures, physicochemical, biological, and therapeutic properties, indicating the broad specificity of P-gp modulators (Fig. 1). LS-180, a human colon adenocarcinoma cell line (23), was chosen as a model cell line to study the up-regulation of P-gp because of its endogenous expression of pregnane$\mathrm{X}$-receptor (PXR), a nuclear hormone receptor controls expression of drug metabolizing enzymes and efflux transporters including P-gp $(24,25)$. Concentration-response studies were conducted to determine the potency of rifampicin, dexamethasone, hyperforin, pentylenetetrazole, $\beta$ estradiol, verapamil, and caffeine to up-regulate P$\mathrm{gp}$ in vitro. To determine the functional significance of this up-regulation, the intracellular accumulation of P-gp substrate was evaluated by an uptake studies with rhodamine 123 as a P-gp substrate. To our knowledge, this is the first report which quantitatively evaluates and ranks the inductive potency of selected drugs to up-regulate P-gp over a broad concentration range utilizing the same protocol and experimental conditions.

\section{MATERIAL AND METHODS}

\section{Materials}

Human colorectal adenocarcinoma cell line (LS180 ) and all cell culture reagents, as recommended for the growth and maintenance of LS-180 cells (e.g. culture medium, fetal bovine serum (FBS), penicillin and streptomycin antibiotics, phosphate buffer saline (PBS) and other supplements), were obtained from American Type Culture Collection (Manassas, VA). Rifampicin, dexamethasone, hyperforin, pentylenetetrazole, caffeine, $\beta$-estradiol, verapamil, and Tween 20 were purchased from Sigma-Aldrich (St. Louis, MO). RIPA buffer was purchased from Thermo Scientific (Rockford, IL). The reagents and supplements required for western blotting were purchased from Bio-Rad (Hercules, CA). The anti-P-gp antibody (C-219) was obtained from Covance Research Products (Dedham, MA). Anti- $\beta$-actin (C-11) and HRP-labeled anti-mouse antibodies for P-gp and $\beta$-actin were purchased from Santa Cruz Biotechnology Inc. (Santa Cruz, CA). Forward and reverse primers for MDRl and $G A P D H$ genes were designed and synthesized by Invitrogen (Carlsbad, CA). All other reagents, chemicals and supplies were purchased from VWR (West Chester, PA). 


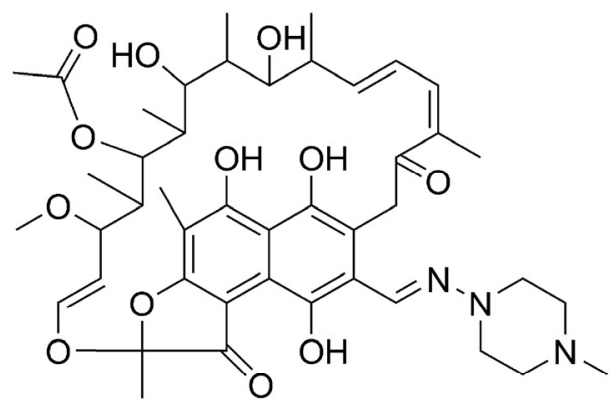

\section{Rifampicin}<smiles>CC12CCC3c4ccc(O)cc4CCC3C1CCC2O</smiles>

$\beta$-Estradiol<smiles>CC1CC2C3CCC4=CC(=O)C=CC4(C)C3(F)C(O)CC2(C)C1(O)C(=O)CO</smiles>

Dexamethasone

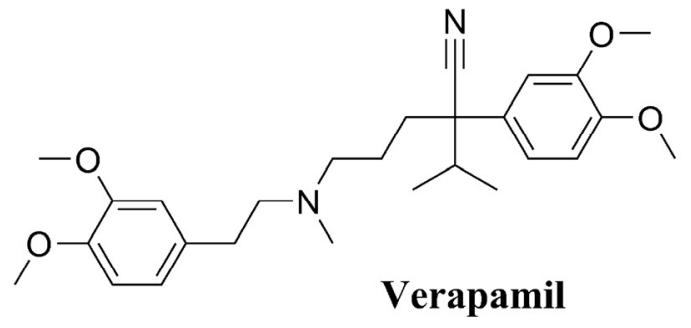

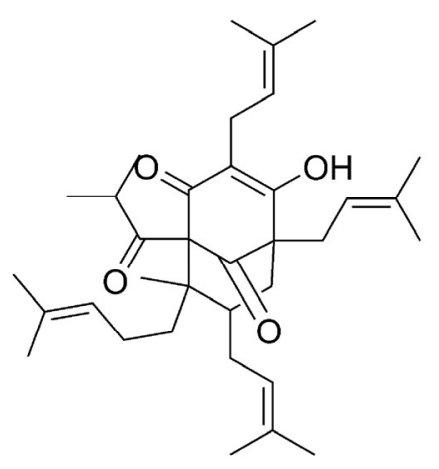

Hyperforin<smiles>Cn1c(=O)c2c(ncn2C)n(C)c1=O</smiles>

Caffeine<smiles>C1CCc2nnnn2CC1</smiles>

Pentylenetetrazole

Figure 1. Chemical structures for the investigated drugs.

\section{Cell Culture}

LS-180 cells were cultured in RPMI-1640 growth medium supplemented with $2 \mathrm{mM}$ L-glutamine, 10 $\mathrm{mM}$ HEPES, $1 \mathrm{mM}$ sodium pyruvate, $4500 \mathrm{mg} / \mathrm{L}$ glucose, $1500 \mathrm{mg} / \mathrm{L}$ sodium bicarbonate, $10 \% \mathrm{FBS}$, $50 \mathrm{IU} / \mathrm{ml}$ penicillin and $50 \mu \mathrm{g} / \mathrm{ml}$ streptomycin. The cells were grown to confluence in $75-\mathrm{cm}^{2}$ cell culture flasks for 3-6 days in a humidified atmosphere at $37^{\circ} \mathrm{C}$ and $5 \% \mathrm{CO}_{2}$ and used between passage numbers 5-20.
Drug treatment of LS-180 for in vitro induction study

Cells were seeded in $10 \mathrm{~mm}$-cell culture dishes at a density of $5 \times 10^{6}$ cells/dish and allowed to attach and grow up to $50-60 \%$ confluence in a humidified atmosphere at $37^{\circ} \mathrm{C}$ and $5 \% \mathrm{CO}_{2}$. Stock solutions of rifampicin, pentylenetetrazole, $\beta$-estradiol (all dissolved in DMSO), in addition to dexamethasone and verapamil (dissolved in methanol) and caffeine (dissolved in water) were diluted to a final 
concentration of 5-100 $\mu \mathrm{M}$ in growth medium before use. Hyperforin methanolic stock solution was diluted in growth medium to a final concentration of 25-150 nM. Forty eight hours after cell seeding, media containing various drugs at different concentrations in addition to control medium (containing either DMSO or methanol) were added to the respective treatment cells in duplicate at a maximum DMSO or methanol concentration of $0.2 \%$. The cells were then incubated for $48 \mathrm{~h}$ in a humidified atmosphere at $37^{\circ} \mathrm{C}$ and $5 \% \mathrm{CO}_{2}$. The media were not renewed for the duration of the experiment.

\section{Cells harvesting and lysis}

After $48 \mathrm{~h}$ incubation, the cells were harvested and lysed as follows: the cells were initially washed twice using ice-cold PBS, scraped, and centrifuged at $5000 \mathrm{rpm}$ for $10 \mathrm{~min}$ at $4^{\circ} \mathrm{C}$. The cells pellets were then re-suspended and homogenized in RIPA buffer or RLT lysis buffer (Qiagen Sciences Inc., Valencia, CA) for the extraction of protein and mRNA, respectively. The samples were then centrifuged at $12,000 \mathrm{rpm}$ for $10 \mathrm{~min}$ at $4^{\circ} \mathrm{C}$. The lysate samples were stored at $-80^{\circ} \mathrm{C}$ for subsequent protein and mRNA analyses.

\section{Western blot analysis of P-gp}

The analysis of P-gp expression in LS-180 cells was performed as follows: After $48 \mathrm{~h}$ of drug treatment, total protein extracts has been obtained from the harvested LS-180 cells as described above. The protein concentrations were determined using Pierce bicinchoninic acid (BCA) protein assay kit (Thermo Scientific) according to the manufacturer's instruction using bovine serum albumin (BSA) as a standard. Sixteen micrograms of the protein extracts were 1:1 diluted with Laemmli sample buffer and resolved using 7.5\% SDS-polyacrylamide gel with a $5 \%$ stacking gel at $140 \mathrm{~V}$ for $1 \mathrm{~h}$. The molecular weight of the proteins was determined using a recombinant prestained protein marker (Precision Plus Protein Kaleidoscope standards, Bio-Rad). Proteins were transferred electrophoretically onto a nitrocellulose membrane at $300 \mathrm{~mA}$ for $1.5 \mathrm{~h}$. The membrane was blocked with $2 \%$ BSA/PBS for $1 \mathrm{~h}$ at room temperature and then incubated with primary antibodies for P-gp (C-219) and $\beta$-actin (C11) at dilutions $1: 200$ and $1: 3000$, respectively, in PBS containing $2 \%$ BSA and $0.05 \%$ Tween-20 overnight at $4^{\circ} \mathrm{C}$. For proteins detection, the membrane was subsequently incubated with secondary anti-mouse IgG antibody for P-gp and anti-goat IgG antibody for $\beta$-actin, both labeled with horseradish peroxidase (HRP), at 1:5000 dilution in PBS containing 2\% BSA and $0.05 \%$ Tween-20 for $1 \mathrm{~h}$ at room temperature. The blots were developed using a chemiluminescence detection kit (Pierce ECL Western Blotting Substrate, Thermo Scientific). Quantitative analysis of the immunoreactive bands was performed using Syngene luminescent image analyzer (Scientific Resources Southwest, Inc., Stafford, TX). The results of protein quantification were expressed as the ratio of $\mathrm{P}-\mathrm{gp}$ to $\beta$-actin levels.

\section{Quantitative real time PCR}

mRNA levels of MDR1 and GAPDH were quantified using SYBR based real time quantitative PCR assay as follows: Total mRNA extracts were obtained from the harvested LS-180 cells as described above. The mRNA was isolated and purified using RNeasy Mini Kit (Qiagen Sciences Inc) according to the manufacturer's instruction. The concentration of isolated mRNA samples was carried out using SmartSpec Plus spectrophotometer at $260 \mathrm{~nm}$ (Bio-Rad). The purity of mRNA was confirmed by measuring A260/280 ratio and the values were between 1.8 and 2.0. Equal amounts of mRNA (250 ng) were reverse transcribed to cDNA using TaqMan reverse transcription reagents and random hexamer reverse transcription primers (Applied Biosystems, Branchburg, NJ) under the following parameters: $25^{\circ} \mathrm{C}$ for $10 \mathrm{~min}, 48^{\circ} \mathrm{C}$ for $30 \mathrm{~min}$, and $95^{\circ} \mathrm{C}$ for 5 min. Using the MDRl forward primer (5'TGAAGTCCTCTGGCAAGTCC-3') and its reverse primer (5'-ATTCTCCCTCCCGGTTCC3'), a 206-bp PCR fragment of MDRl gene was amplified using IQ SYBR Green SuperMix with MyiQ Real-Time PCR Detection System from BioRad. GAPDH was used as an internal control for normalization using the forward primer (5'CCAGGGCTGCTTTTAACTC-3') and reverse primer (5'-GCTCCCCCCTGCAAATGA-3'). Cycling parameters were as follows: denaturing at $95^{\circ} \mathrm{C}$ for $10 \mathrm{sec}(1 \mathrm{cycle})$, and then annealing and extending at $95^{\circ} \mathrm{C}$ and $60^{\circ} \mathrm{C}$ for 15 and $60 \mathrm{sec}$, respectively (40 cycles). Specific amplification was confirmed by melting curve analysis. The $\mathrm{C}_{t}$ for each sample was normalized against that of $G A P D H$. Folds change was determined relative to 
the control using the comparative threshold cycle method $\left(2^{-\Delta \Delta \mathrm{Ct}}\right)$. All the results were expressed as means and standard deviation compared to control.

\section{Drug treatment of LS-180 for in vitro activity study}

Cells were seeded in 48-well plates at a density of $5 \times 10^{4}$ cells/well and allowed to attach and grow to $50-60 \%$ confluence at $37^{\circ} \mathrm{C}$ in a humidified atmosphere of $5 \% \mathrm{CO}_{2}$. The cells were then treated as described previously in the in vitro induction study section. Similar concentrations were used as for the expression studies except for verapamil where it was examined up to $200 \mu \mathrm{M}$.

\section{In vitro activity study of $P$-gp in LS-180 cells}

The activity of the induced P-gp in LS-180 cells was evaluated by an uptake study to measure the accumulation of P-gp substrate within the LS-180 cells as follows: After $48 \mathrm{~h}$ of drug treatment in 48 well plates, the treatment medium was aspirated and the cells were incubated in fresh growth medium for $4 \mathrm{~h}$. This incubation step was important in order to minimize the inhibitory effect some drugs, such as rifampicin, verapamil and caffeine, may have on P-gp. After incubation, the cells were washed three times with a transport buffer $(141 \mathrm{mM}$ $\mathrm{NaCl}, 4 \mathrm{mM} \mathrm{KCl}, 2.8 \mathrm{mM} \mathrm{CaCl}_{2}, 1 \mathrm{mM} \mathrm{MgSO}_{4}, 10$ $\mathrm{mM}$ D-Glucose, and $10 \mathrm{mM}$ HEPES). The cells were then pre-incubated with or without $100 \mu \mathrm{M}$ verapamil in transport buffer for $30 \mathrm{~min}$. The activity experiments were started by the addition of $1 \mu \mathrm{g} / \mathrm{ml}$ of rhodamine 123 in transport buffer with or without $100 \mu \mathrm{M}$ verapamil for $2 \mathrm{~h}$ at $37^{\circ} \mathrm{C}$ in a humidified atmosphere of $5 \% \mathrm{CO}_{2}$. The activity experiment was then terminated by washing the cells three times with ice-cold PBS and then disrupting them with an in-house lysis buffer $(0.8 \mathrm{~g}$ sodium hydroxide and $0.5 \mathrm{ml}$ Triton X-100 dissolved in $100 \mathrm{ml}$ of water) for $1 \mathrm{~h}$ at $37^{\circ} \mathrm{C}$. The fluorescent intensity of rhodamine 123 accumulated inside the cells were measured using Synergy 2 microplate reader (Biotek, Winooski, VT) under the excitation wavelength $485 \mathrm{~nm}$ and emission wavelength $529 \mathrm{~nm}$ and data acquisition was achieved using Gene5 software (Biotek). The data were normalized for the protein content. Cellular accumulation of rhodamine 123 was used to calculate the inhibition ratio, which is the ratio of fluorescent intensity per $\mathrm{mg}$ protein of the treatment sample in the presence of verapamil divided by the fluorescent intensity per mg protein of the same sample in the absence of verapamil. All the results were expressed as means and standard deviation (SD) for the inhibition ratios compared to control.

\section{STATISTICAL ANALYSIS}

Wherever possible, the experimental results were analyzed for statistically significant difference using Two-tailed unpaired Student's $t$-test to evaluate differences between controls and treated groups. $\mathrm{E}_{\max }$ and $\mathrm{EC}_{50}$ were determined from nonlinear regression of concentration vs. fold increase curves using the four-parameter Hill equation by GraphPad Prism version 4.0 for Windows (GraphPad Software Inc., San Diego, CA). A $p$ value less than 0.05 was considered to be statistically significant.

\section{RESULTS}

\section{In vitro induction of $\mathrm{P}$-gp expression}

The ability of these drugs at different concentrations to induce P-gp expression was assessed by Western blotting using the C-219 antibody. Figures 2 and 3 (solid columns, left Y axis) illustrate Western blots for P-gp expression in LS-180 cells treated with increasing concentrations of rifampicin, dexamethasone, verapamil and hyperforin as representative drugs, and fold increase in P-gp expression quantified by densitometry from the immunoblots, respectively. All investigated drugs resulted in a concentrationdependent increase in P-gp expression in LS-180 cells following $48 \mathrm{~h}$ incubation period. Under the in vitro cell culture conditions, about 4-7-fold increase in the expression of P-gp protein was observed post-incubation with rifampicin (Fig. 2 \& 3A), while verapamil increased P-gp expression by 2 to 3.4-fold compared to control throughout the entire concentration range (Fig. $2 \& 3 \mathrm{~B}$ ). Hyperforin, the active component of St John's Wort, showed up to 3 -fold increase in the examined range (Fig. 2 \& 3F). For other investigated drugs including dexamethasone, pentylenetetrazole and $\beta$-estradiol, only concentrations at $50 \mu \mathrm{M}$ and higher resulted in up-regulation of P-gp protein levels (up to $\sim 2$-fold, Fig. C-E). On the other hand, caffeine resulted in a modest induction effect on P-gp expression (20$40 \%$ in the concentration range $5-100 \mu \mathrm{M}$, Fig. $3 \mathrm{G}$ ). 


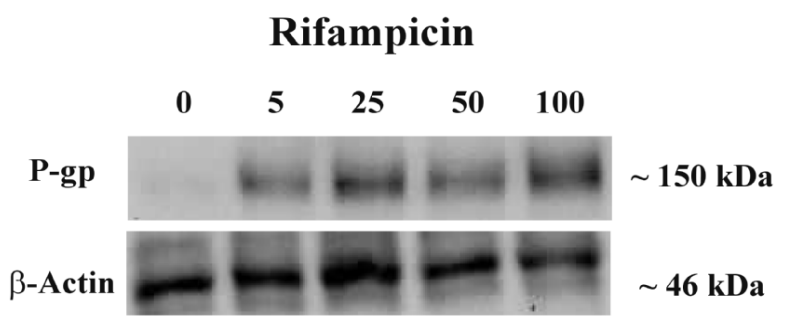

Dexamethasone

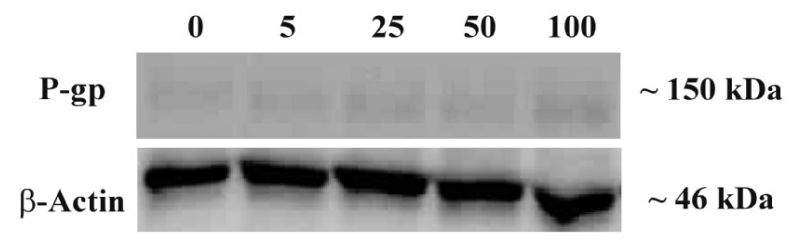

Verapamil

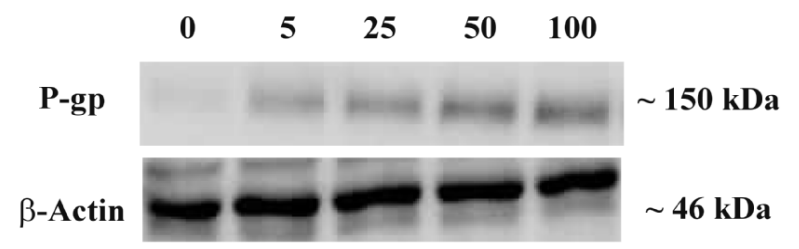

Figure 2. Representative Western blots for P-gp in LS-180 cells treated with rifampicin, verapamil, dexamethasone, and hyperforin. Cells were treated for $48 \mathrm{~h}$ with increasing concentrations of the indicated drugs in the range of 5-100 $\mu \mathrm{M}$ except for hyperforin (25-150 nM). P-gp protein expression was analyzed by immunoblotting with C-219 primary antibody.

In vitro up-regulation of $M D R 1$ gene expression In addition to P-gp expression, mRNA levels of MDR1 in LS-180 cells were also measured following $48 \mathrm{~h}$ treatment with rifampicin, dexamethasone, caffeine, pentylenetetrazole, verapamil, and $\beta$-estradiol at $50 \mu \mathrm{M}$ concentrations, and hyperforin at $0.1 \mu \mathrm{M}$. The fold increase in MDR 1 mRNA level caused by the examined drugs were in the following order: rifampicin (6.2-fold) $>$ $\beta$-estradiol $(\sim 4$-fold $)>$ pentylenetetrazole $\approx$ hyperforin $(\sim 3$-fold $)>\operatorname{verapamil}(2.2$-fold $) \approx$ dexamethasone and caffeine (2.1-fold).

\section{Evaluation of P-gp functionality following its induction}

To determine the functional significance of this increase in P-gp expression, the cellular uptake of P-gp substrate rhodamine 123 was evaluated at the above examined concentration ranges of the expression studies in the presence and absence of verapamil (100 $\mu \mathrm{M}$, as a P-gp inhibitor). A significant increase in rhodamine 123 accumulation by LS- 180 cells was observed in the presence of the P-gp inhibitor compared to its absence, confirming specific functional activity of P-gp as explanation for the decreased intracellular rhodamine 123 caused by drugs treatments. Figure 3 (A-G) demonstrates the fold increase in P-gp activity (lines, right $\mathrm{Y}$ axis) following LS-180 cells treatment with rifampicin, verapamil, dexamethasone, pentylenetetrazole, $\beta$-estradiol, caffeine, and hyperforin. Increases in P-gp expressions were associated with an increase in Pgp transport activity, measured as the ratio of intracellular rhodamine 123 fluorescence in the presence and absence of $100 \mu \mathrm{M}$ verapamil. Under control conditions (i.e. without treatment), LS-180 cells exhibit a low level of P-gp expression and function that was significantly increased following treatment with the examined drugs. The effect of rifampicin on P-gp activity in LS-180 cells increased progressively $(60-290 \%)$ over the range 5-100 $\mu \mathrm{M}$ (Fig. 3A). A similar profile was seen, however to a lesser extent, with verapamil over the concentration range 5-200 $\mu \mathrm{M}(18-120 \%$ increase, Fig. 3B). Cells treated with dexamethasone and $\beta$ estradiol increased P-gp activity by $>50 \%$ at $5 \mu \mathrm{M}$ and this activity increased with concentration, while with pentylenetetrazole P-gp activity increased by $80 \%$ in the concentration range $25-100 \mu \mathrm{M}$ (Fig. 3C-E). Hyperforin, examined in $\mathrm{nM}$ concentration range increased P-gp activity by $110 \%$ at $50 \mathrm{nM}$ up to $190 \%$ at $150 \mathrm{nM}$ (Fig. 3F); and caffeine significantly increased P-gp activity by $250-300 \%$ in the concentration range $25-100 \mu \mathrm{M}$ (Fig. 3G). 


\section{Rifampicin}

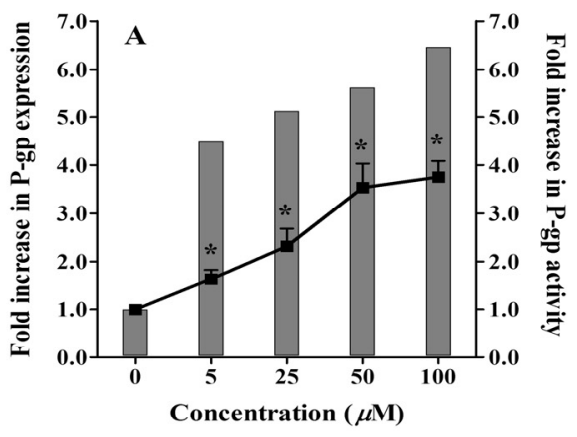

Dexamethasone

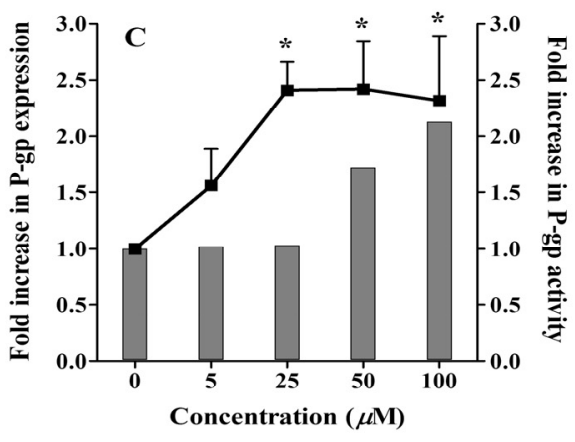

$\beta$-Estradiol

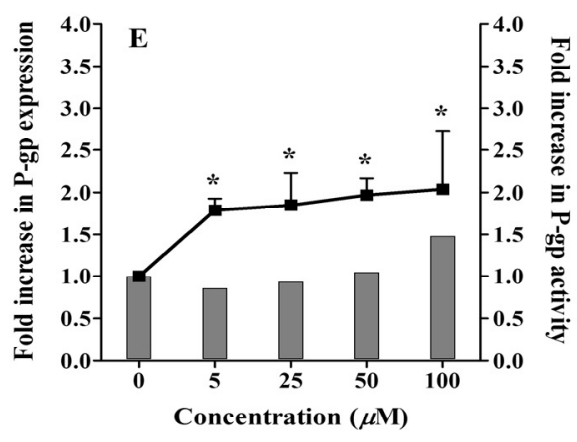

Verapamil

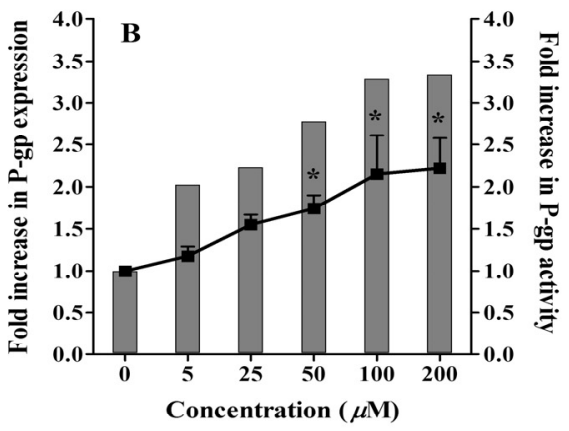

Pentylenetetrazole

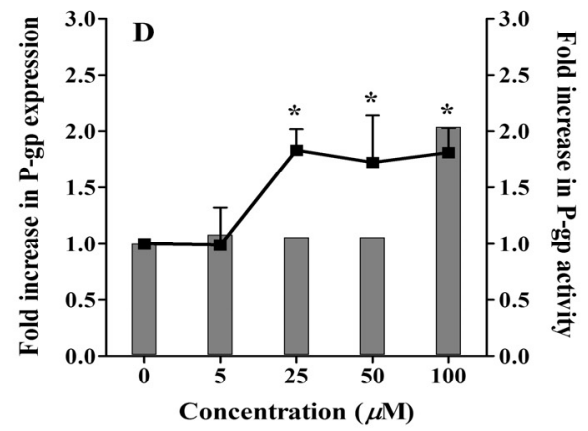

Hyperforin

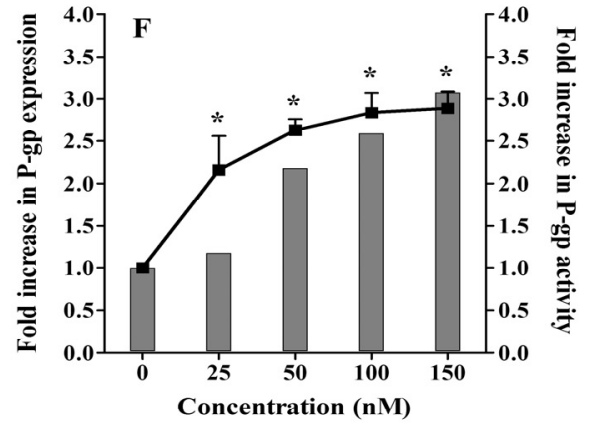

Caffeine

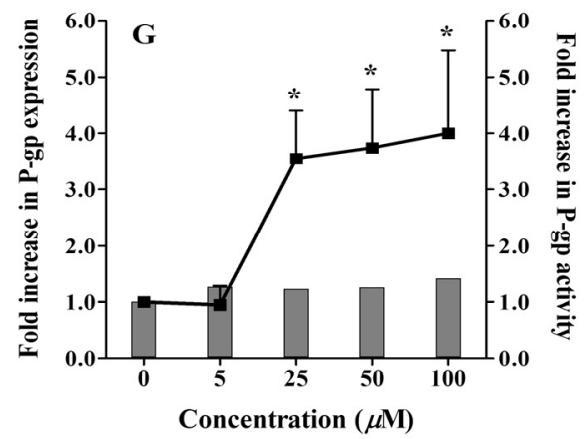

Figure 3. Effect of treatment of LS-180 cells with increasing concentrations of (A) rifampicin, (B) verapamil, (C) dexamethasone, (D) pentylenetetrazole, (E) $\beta$-estradiol, (F) hyperforin, and (G) caffeine, on P-gp expression and activity. Cells were treated for $48 \mathrm{~h}$ followed by Western blot analysis for P-gp expression (shown as column bars) and uptake study for P-gp activity (shown as line). P-gp activity was measured as the ratio of intracellular rhodamine 123 fluorescence in the presence and absence of $100 \mu \mathrm{M}$ verapamil as P-gp inhibitor. The data is expressed as mean \pm STD for P-gp activity $(\mathrm{n}=3$ 4). $\mathrm{P}$-gp expression was determined for $\mathrm{n}=2 .{ }^{*} P<0.05$. 
Figure 4 compares the expression of P-gp, MDR1 mRNA and associated activity after exposure to the drugs at $50 \mu \mathrm{M}$. LS-180 cells treated with rifampicin, verapamil and dexamethasone induced both P-gp expression (transcript and protein) as well as activity to variable degrees. At $50 \mu \mathrm{M}$ concentration, rifampicin induced $M D R 1$ mRNA, P-gp expression and activity by 6.2-, 5.6-, and 2.9-fold, respectively. At the same concentration, dexamethasone and verapamil increased MDR1 mRNA by 2.1 - and 2.2fold, P-gp expression by 1.72- and 3.3-fold and activity by $2.4-$ and 1.7 -fold, respectively. On the other hand, hyperforin at $0.1 \mu \mathrm{M}$ induced P-gp transcript, expression and activity to a comparable degree of 3.2-, 2.6- and 2.8-fold, respectively. For cells treated with $\beta$-estradiol and pentylenetetrazole, while the increase in P-gp expression was negligible $(\sim 10 \%)$, both drugs resulted in significant induction in MDR1 mRNA ( $\sim 3$-4-fold), and activity (100 and $70 \%$ for $\beta$-estradiol and pentylenetetrazole, respectively). In the case of caffeine, the increase in P-gp expression was minor (25\%), however, at $50 \mu \mathrm{M}$ concentration it increased MDR1 mRNA levels by $\sim 2.1$-fold, and activity by 3.7 -fold.

\section{Determination of $\mathbf{E C}_{\mathbf{5 0}}$}

From the concentration-dependent activity study the $\mathrm{EC}_{50}$ of each inducer was determined from the average of fold increase in P-gp activity. The Hill equation was fit to the fold increase in P-gp activity as a function of increasing inducer concentration to estimate the $\mathrm{EC}_{50}$ and $\mathrm{E}_{\max }$, from which the induction activity (or potency) was estimated $\left(\right.$ Potency $\left.=\mathrm{E}_{\max } / \mathrm{EC}_{50}\right)$.

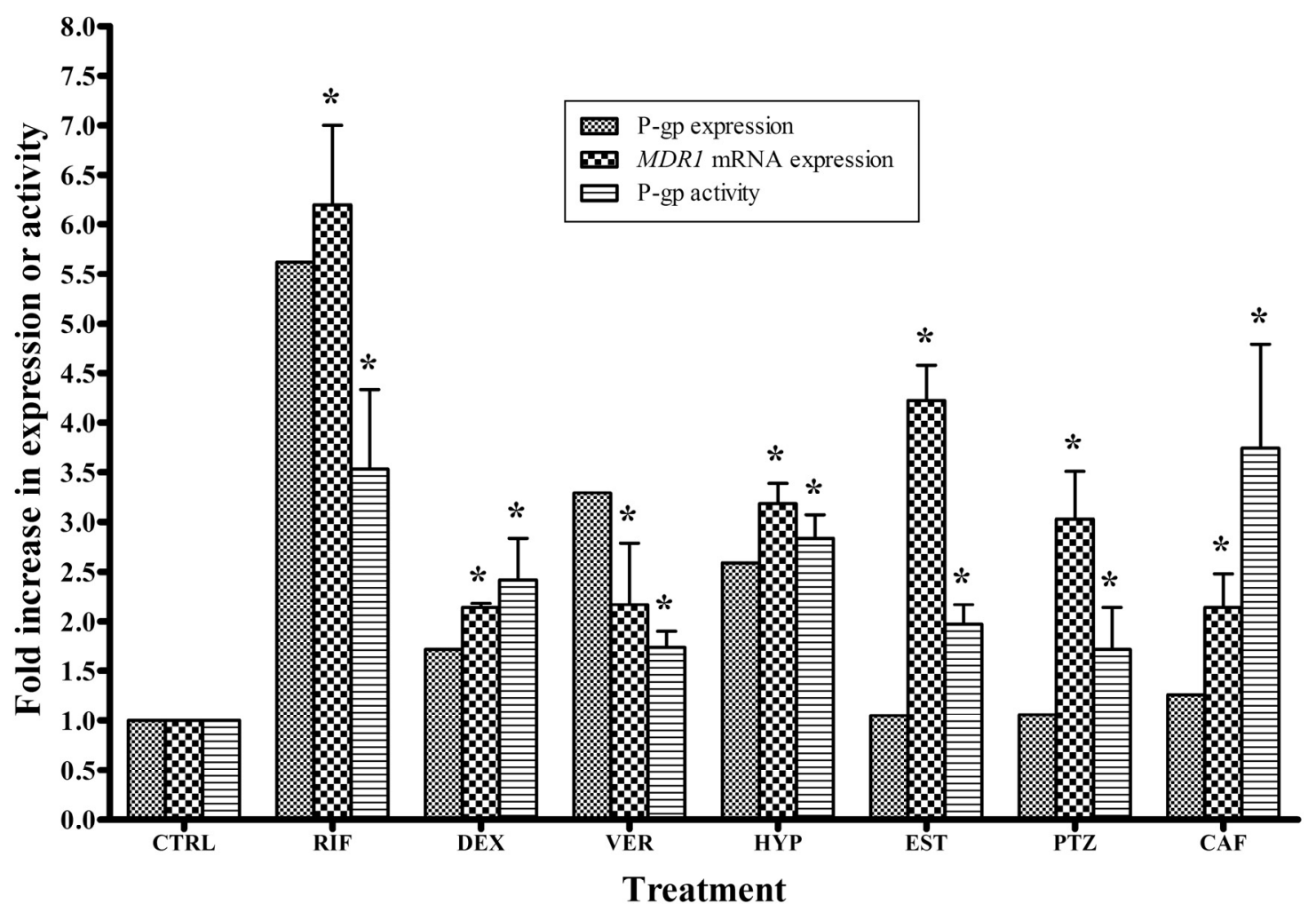

Figure 4. Effect of treatment with rifampicin (RIF), dexamethasone (DEX), verapamil (VER), hyperforin (HYP), $\beta$ estradiol (EST), pentylenetetrazole (PTZ), and caffeine (CAF) on P-gp expression, MDR1 mRNA expression and activity in LS-180 cells compared to control (CTRL). The drugs indicated were incubated with LS-180 cells at $50 \mu \mathrm{M}$ for $48 \mathrm{~h}$. P-gp protein expression was analyzed using Western blotting, MDRI mRNA was quantified using real-time PCR analysis, and P-gp activity was estimated utilizing uptake studies utilizing rhodamine 123 as P-gp substrate $(1 \mu \mathrm{g} / \mathrm{ml})$. The data is expressed as mean \pm STD for MDRl mRNA expression $(n=3)$ and P-gp activity $(\mathrm{n}=3-4)$. P-gp expression was determined for $\mathrm{n}=2 . * P<0.05$. 
The results, listed in Table 1, illustrated the in vitro potencies of the inducers to up-regulate P-gp activity was in the following order: hyperforin $>>>$ dexamethasone $\approx \beta$-estradiol $>$ caffeine $>$ rifampicin $\approx$ pentylenetetrazole $>$ verapamil.

For comparison and correlation purposes with the activity data, drugs $\mathrm{EC}_{50}$ to up-regulate $\mathrm{P}$-gp expression following normalization to $100 \%$ (as expression increase did not reach plateau) were calculated and were in the following order: hyperforin $(5 \mathrm{nM})>>$ verapamil $(4.4 \mu \mathrm{M}) \approx$ rifampicin $(5 \mu \mathrm{M})>$ caffeine $(9.1 \mu \mathrm{M})>$ dexamethasone $\left(\begin{array}{ll}46 & \mu \mathrm{M})\end{array}\right) \beta$-estradiol $\approx$ pentylenetetrazole $(>50 \mu \mathrm{M})$, compared to the activity $\mathrm{EC}_{50}$ values (Table 1): hyperforin $>>>\beta$ estradiol $>$ dexamethasone $>$ pentylenetetrazole $>$ caffeine $>$ rifampicin $>$ verapamil. The $\mathrm{EC}_{50}$ comparison clearly demonstrate a lack of correlation in drugs potencies to up-regulate P-gp at the expression and activity levels; however activity studies are considered the reliable predictors of Pgp functional up-regulation.

\section{DISCUSSION}

The involvement of P-gp in the active efflux of a diverse range of compounds is now wellestablished (26). P-gp expression and function have also been shown to be modulated pharmacologically by diverse compounds $(26,27)$. While most of the in vitro P-gp modulation studies focused on its inhibition (12), fewer studies have investigated the induction effect of individual drugs on P-gp expression and/or activity $(17-19,28,29)$. In most of these studies, the P-gp induction effect by different treatments was examined at a single concentration for each drug and the concentrations varied from 10 to $300 \mu \mathrm{M}(17,19,28)$. Thus, in the current study we aimed to in vitro screen known and new inducers for their induction effect on both P-gp expression and activity at different concentrations in the range 5-100 $\mu \mathrm{M}$, except for hyperforin, which was examined in the range 25$150 \mathrm{nM}$. When drugs are taken orally their concentrations will be in the low to high $\mathrm{mM}$ range in the intestine that will be further diluted following absorption into the circulation through the liver and then distributed to the other organs. Thus, to cover that wide range we conducted our experiment in the ranges indicated above. We attempted to go higher than $100 \mu \mathrm{M}$ for some drugs; however it was toxic to the cells. The drugs were then ranked according to their $\mathrm{E}_{\max } / \mathrm{EC}_{50}$ ratio as a measure for their potency to up-regulate P-gp activity under the same experimental conditions.

We have demonstrated that exposure of LS-180 cells to rifampicin, dexamethasone, verapamil, hyperforin, $\beta$-estradiol, pentylenetetrazole and caffeine for $48 \mathrm{~h}$ resulted in a concentrationdependent increase in P-gp expression and an increase in MDRl mRNA levels at $50 \mu \mathrm{M}$ concentrations (hyperforin, $0.1 \quad \mu \mathrm{M}$ ).

Table 1. In vitro $\mathrm{EC}_{50}, \mathrm{E}_{\max }$ and potency values of the $\mathrm{P}$-gp inducers tested. The ratios $\mathrm{E}_{\max } / \mathrm{EC}_{50}$ provide a rank order for drugs potencies to up-regulate P-gp in LS-180 cells.

\begin{tabular}{cccc}
\hline Drug & $\mathrm{EC}_{50}(\mu \mathrm{M})$ & $\begin{array}{c}\mathrm{E}_{\max } \\
(\text { fold } \uparrow \text { in P-gp activity) }\end{array}$ & $\mathrm{E}_{\max } / \mathrm{EC}_{50}$ \\
\hline Rifampicin & 26.0 & 4.4 & 0.17 \\
Dexamethasone & 4.4 & 2.5 & 0.57 \\
Verapamil & 48.2 & 2.6 & 0.05 \\
Caffeine & 15.5 & 3.9 & 0.25 \\
Pentylenetetrazole & 11.8 & 2.0 & 0.17 \\
Hyperforin & 0.02 & 2.9 & 145 \\
$\beta$-Esttradiol & 3.5 & 1.9 & 0.54 \\
\hline
\end{tabular}


Prior experiments were conducted to optimize the treatment time and found that for most of the drugs investigated in this study $48 \mathrm{~h}$ treatment resulted in maximum P-gp expression induction with minimal cells toxicity (data not shown). In addition, consistent with the expression studies, the activity studies demonstrated concentration-dependent increases in P-gp activity, however to a variable extent. The functionality of P-gp in these cells was demonstrated by rhodamine 123 accumulation, which decreased by drugs treatments and increased by P-gp inhibition by verapamil suggesting the increase in P-gp activity. Verapamil, when added simultaneously with a P-gp substrate to the cells, has been described as a specific competitive inhibitor for P-gp but not BCRP $(30,31)$, and is commonly used to evaluate the functionality of $\mathrm{P}$ gp efflux transporter using rhodamine 123 as a substrate $(17,32-36)$.

The in vitro induction in P-gp activity and/or expression findings observed with rifampicin, verapamil, hyperforin, dexamethasone and $\beta$ estradiol are in agreement with other studies (17-19, 28, 29); however the magnitude in fold increase varies; that validates and supports the aim of the current study to use similar in vitro conditions to rank drugs potencies to up-regulate P-gp. Such differences could be related to the use of different cell lines, variability in cell culture conditions, cells passage numbers and/or the protocol used. Furthermore, to our knowledge this is the first report showing the concentration-dependent increase in both P-gp expression and activity in LS180 following treatment with caffeine or pentylenetetrazole. Caffeine and pentylenetetrazole have significantly decreased rhodamine 123 accumulation in a concentration-dependent manner. Caffeine was selected in this study because it is the most widely consumed psychoactive substance, and yet studies investigating its effect on P-gp modulation are not available. Several studies have reported caffeine to interact with a wide range of drugs, including antidepressant, antipsychotic and sedative drugs. Such interactions may lead to caffeine-related or drug-related adverse effects that can complicate psychiatric treatment (37). Available studies showed the effect of xanthine derivatives on the antitumor activities of doxorubicin (38). Xanthine derivatives, including caffeine, when combined with doxorubicin, enhanced the uptake and antitumor activity of doxorubicin in tumors (38). These actions are believed to be related to the inhibitory activity of caffeine on doxorubicin efflux from tumor cells by P-gp. Like verapamil, caffeine when simultaneously exists with a P-gp substrate it acts as inhibitor of Pgp increasing the P-gp substrate intracellular uptake. In addition, Kaddoumi et al. reported the possible role of caffeine as a P-gp inhibitor at the rat BBB when combined with phenylpropanolamine (PPA) (39). Under these conditions, treatment with caffeine caused an increase in PPA levels in the rat brain. As P-gp inducer, to our knowledge only one study reported caffeine to moderately up-regulate $\mathrm{P}$ gp at $1 \mathrm{mM}$ concentration (40). In the present study, we have shown caffeine as an inducer of P-gp expression $\left(\mathrm{EC}_{50}=15.3 \mu \mathrm{M}\right)$, transcript, and activity $\left(\mathrm{EC}_{50}=9.1 \mu \mathrm{M}\right)$ over a wide range. Our results signify the potential role of caffeine to upregulate P-gp expression and activity, suggesting its possible participation in drug interactions, even at lower concentrations than previously reported (40), when administered with other drugs that are P-gp substrates affecting their disposition and thus efficacy.

Pentylenetetrazole, on the other hand, at nonepileptic doses was found to restore the cognitive function (learning and memory) of a Down syndrome mouse model by inhibiting $\mathrm{GABA}_{\mathrm{A}}$ receptor without inducing seizures (41). Experimentally induced seizures in rats by chronic pentylenetetrazole-kindling resulted in increased Pgp expression and function in the rat brain (42). While the authors in Liu et al. study did not report whether such increase in P-gp expression and function is a result of seizure's induction or treatment with pentylenetetrazole, our results from the in vitro studies have shown that LS-180 cells treated with pentylenetetrazole increased P-gp expression and activity in a concentrationdependent manner, however to a lesser extent than other investigated drugs. Pentylenetetrazole increased P-gp activity by $\sim 80 \%$ at concentrations $\geq$ $25 \mu \mathrm{M}\left(\mathrm{EC}_{50}=11.8 \mu \mathrm{M}\right)$, while increased P-gp expression by $100 \%$ only at $100 \mu \mathrm{M}\left(\mathrm{EC}_{50}>50\right.$ $\mu \mathrm{M})$.

The fold increase in P-gp activity by hyperforin was consistent with the increase in P-gp expression ( $\sim 3$-fold); however, the magnitude of induction in P-gp activity by $\beta$-estradiol, pentylenetetrazole and caffeine was higher than the protein expression. Although the explanation for this result is not clear, 
at $50 \mu \mathrm{M}$ concentrations there appeared to be a close correlation between MDRI mRNA and activity in LS-180 cells compared to P-gp protein expression. While such negligible effect on P-gp protein expression, by caffeine for example, could be related to the sensitivity of Western blotting technique, our results suggest that changes in mRNA levels could be the appropriate quantitative indicator of alteration in P-gp transport activity (Fig. 4) (17). This observation is further supported by the lack of correlation in the $\mathrm{EC}_{50}$ values of these drugs to up-regulate P-gp activity and protein expression. While hyperforin showed to be the most potent to induce activity and expression, the rank order of other drugs potencies to induce the activity of P-gp and its expression differ. For example, activity studies concluded verapamil as the least potent, however expression studies showed verapamil ability to induce P-gp by $\sim 3$ fold with an $\mathrm{EC}_{50}$ of $4.4 \mu \mathrm{M}$, and unlike the activity data $\beta$ estradiol and pentylenetetrazole to be the least potent to increase P-gp expression. The above results indicate utilization of changes in P-gp expression as a marker for activity in induction studies is not conclusive and the lack of significant increase in P-gp expression doesn't exclude the possibility of drug interaction. Moreover, the in vitro activity studies demonstrated that drugs examined in this study have the potential to play role in drug interactions with hyperforin being the most potent and verapamil is the least. Clinically, the chronic use of hyperforin has shown to interact with a number of drugs by reducing their bioavailability as a result of P-gp induction. Such drugs include the HIV protease inhibitor indinavir and the cardiac glycoside digoxin in human volunteers $(43,44)$. In these studies, hyperforin plasma concentration was reported around 25-30 $\mathrm{nM}$ (43), which is higher than its estimated $\mathrm{EC}_{50}$ in the current study (20 nM, Table 1). In addition, rifampicin has been reported to alter the human pharmacokinetics and pharmacodynamics of glyburide (45), and talinolol (46) via P-gp induction. Following $600 \mathrm{mg}$ dose, rifampicin plasma concentrations have been reported in the range 5-38 $\mu \mathrm{M}$, average $21.5 \mu \mathrm{M}$ (Facts \& Comparisons $4.0^{\mathbb{R}}$, online edition), which is approximately similar to the estimated $\mathrm{EC}_{50} \quad(26$ $\mu \mathrm{M})$. However, for other drugs investigated including verapamil, dexamethasone, $\beta$-estradiol, pentylenetetrazole and caffeine, whether their induction effect on P-gp expression and/or activity is clinically significant or not remain to be investigated. Nevertheless, their potential association with drug interactions should not be ignored, especially caffeine with an estimated $\mathrm{EC}_{50}$ of $15.5 \mu \mathrm{M}$ (Table 1), which is lower than the reported plasma concentration in the range 25-130 $\mu \mathrm{M}$ after $250 \mathrm{mg}$ dose (Facts \& Comparisons $4.0^{\circledR}$, online edition).

In conclusion, our study shows in vitro concentration-dependent increase in P-gp expression and activity by various drugs, including rifampicin, verapamil, hyperforin, dexamethasone, caffeine, $\beta$-estradiol and pentylenetetrazole. The results suggest these drugs have the potential to produce drug interactions when administered with other drugs that are P-gp substrates. Further studies are needed to in vivo evaluate these drugs and verify the consequences of such induction on P-gp activity and to possible establishing an in vitro-in vivo correlation.

\section{ACKNOWLEDGEMENT}

This research was supported by the National Center for Research Resources (Grant P20RR016456).

\section{REFERENCES}

1. Huang, S.M., J.M. Strong, L. Zhang, et al. New era in drug interaction evaluation: US Food and Drug Administration update on CYP enzymes, transporters, and the guidance process. J Clin Pharmacol, 2008; 48(6): p. 662-70.

2. Boobis, A., J.B. Watelet, R. Whomsley, et al. Drug interactions. Drug Metab Rev, 2009; 41(3): p. 486527.

3. Bodo, A., E. Bakos, F. Szeri, et al. The role of multidrug transporters in drug availability, metabolism and toxicity. Toxicol Lett, 2003; 140141: p. 133-43.

4. Lin, J.H. Drug-drug interaction mediated by inhibition and induction of P-glycoprotein. Adv Drug Deliv Rev, 2003; 55(1): p. 53-81.

5. Koren, G., C. Woodland, and S. Ito. Toxic digoxindrug interactions: the major role of renal $\mathrm{P}$ glycoprotein. Vet Hum Toxicol, 1998; 40(1): p. 45-6.

6. Thiebaut, F., T. Tsuruo, H. Hamada, et al. Cellular localization of the multidrug-resistance gene product P-glycoprotein in normal human tissues. Proc Natl Acad Sci U S A, 1987; 84(21): p. 7735-8.

7. Rengelshausen, J., C. Goggelmann, J. Burhenne, et al. Contribution of increased oral bioavailability and reduced nonglomerular renal clearance of digoxin to 
the digoxin-clarithromycin interaction. $\mathrm{Br} \mathrm{J}$ Clin Pharmacol, 2003; 56(1): p. 32-8.

8. Ihnat, M.A., A.M. Nervi, S.P. Anthony, et al. Effects of mitomycin $\mathrm{C}$ and carboplatin pretreatment on multidrug resistance-associated P-glycoprotein expression and on subsequent suppression of tumor growth by doxorubicin and paclitaxel in human metastatic breast cancer xenografted nude mice. Oncol Res, 1999; 11(7): p. 303-10.

9. Loscher, W. and H. Potschka. Role of drug efflux transporters in the brain for drug disposition and treatment of brain diseases. Prog Neurobiol, 2005; 76(1): p. 22-76.

10. FDA. Guidance for Industry: Drug Interaction Studies-Study Design, Data Analysis, and Implications for Dosing and Labeling. 2006; Available from: http://www.fda.gov/downloads/Drugs/GuidanceCom plianceRegulatoryInformation/Guidances/ucm072101 .pdf.

11. Jodoin, J., M. Demeule, and R. Beliveau. Inhibition of the multidrug resistance P-glycoprotein activity by green tea polyphenols. Biochim Biophys Acta, 2002; 1542(1-3): p. 149-59.

12. Roerig, D.L., S.H. Audi, and S.B. Ahlf. Kinetic characterization of P-glycoprotein-mediated efflux of rhodamine 6G in the intact rabbit lung. Drug Metab Dispos, 2004; 32(9): p. 953-8.

13. Hsiao, P., L. Sasongko, J.M. Link, et al. Verapamil Pglycoprotein transport across the rat blood-brain barrier: cyclosporine, a concentration inhibition analysis, and comparison with human data. J Pharmacol Exp Ther, 2006; 317(2): p. 704-10.

14. Fardel, O., V. Lecureur, and A. Guillouzo. Regulation by dexamethasone of P-glycoprotein expression in cultured rat hepatocytes. FEBS Lett, 1993; 327(2): p. 189-93.

15. Zhao, J.Y., M. Ikeguchi, T. Eckersberg, et al. Modulation of multidrug resistance gene expression by dexamethasone in cultured hepatoma cells. Endocrinology, 1993; 133(2): p. 521-8.

16. Magnarin, M., M. Morelli, A. Rosati, et al. Induction of proteins involved in multidrug resistance ( $\mathrm{P}$ glycoprotein, MRP1, MRP2, LRP) and of CYP 3A4 by rifampicin in LLC-PK1 cells. Eur J Pharmacol, 2004; 483(1): p. 19-28.

17. Collett, A., J. Tanianis-Hughes, and G. Warhurst. Rapid induction of P-glycoprotein expression by high permeability compounds in colonic cells in vitro: a possible source of transporter mediated drug interactions? Biochem Pharmacol, 2004; 68(4): p. 783-90.

18. Narang, V.S., C. Fraga, N. Kumar, et al. Dexamethasone increases expression and activity of multidrug resistance transporters at the rat blood- brain barrier. Am J Physiol Cell Physiol, 2008; 295(2): p. C440-50.

19. Tian, R., N. Koyabu, S. Morimoto, et al. Functional induction and de-induction of P-glycoprotein by St. John's wort and its ingredients in a human colon adenocarcinoma cell line. Drug Metab Dispos, 2005; 33(4): p. 547-54.

20. Perloff, M.D., L.L. von Moltke, and D.J. Greenblatt. Ritonavir and dexamethasone induce expression of CYP3A and P-glycoprotein in rats. Xenobiotica, 2004; 34(2): p. 133-50.

21. Begley, D.J. ABC transporters and the blood-brain barrier. Curr Pharm Des, 2004; 10(12): p. 1295-312.

22. Ghanem, C.I., P.C. Gomez, M.C. Arana, et al. Induction of rat intestinal P-glycoprotein by spironolactone and its effect on absorption of orally administered digoxin. J Pharmacol Exp Ther, 2006; 318(3): p. 1146-52.

23. Tom, B.H., L.P. Rutzky, M.M. Jakstys, et al. Human colonic adenocarcinoma cells. I. Establishment and description of a new line. In Vitro, 1976; 12(3): p. 180-91.

24. Ott, M., G. Fricker, and B. Bauer. Pregnane X receptor (PXR) regulates P-glycoprotein at the bloodbrain barrier: functional similarities between pig and human PXR. J Pharmacol Exp Ther, 2009; 329(1): p. 141-9.

25. Harmsen, S., I. Meijerman, C.L. Febus, et al. PXRmediated induction of P-glycoprotein by anticancer drugs in a human colon adenocarcinoma-derived cell line. Cancer Chemother Pharmacol, 2009.

26. Marchetti, S., R. Mazzanti, J.H. Beijnen, et al. Concise review: Clinical relevance of drug drug and herb drug interactions mediated by the $\mathrm{ABC}$ transporter ABCB1 (MDR1, P-glycoprotein). Oncologist, 2007; 12(8): p. 927-41.

27. Miller, D.S., B. Bauer, and A.M. Hartz. Modulation of P-glycoprotein at the blood-brain barrier: opportunities to improve central nervous system pharmacotherapy. Pharmacol Rev, 2008; 60(2): p. 196-209.

28. Ambroziak, K., K. Kuteykin-Teplyakov, C. LunaTortos, et al. Exposure to antiepileptic drugs does not alter the functionality of P-glycoprotein in brain capillary endothelial and kidney cell lines. Eur J Pharmacol, 2010; 628(1-3): p. 57-66.

29. Coles, L.D., I.J. Lee, P.J. Voulalas, et al. Estradiol and progesterone-mediated regulation of P-gp in P-gp overexpressing cells (NCI-ADR-RES) and placental cells (JAR). Mol Pharm, 2009; 6(6): p. 1816-25.

30. Pham, Y.T., A. Regina, R. Farinotti, et al. Interactions of racemic mefloquine and its enantiomers with P-glycoprotein in an immortalised rat brain capillary endothelial cell line, GPNT. Biochim Biophys Acta, 2000; 1524(2-3): p. 212-9. 
31. Barraud de Lagerie, S., E. Comets, C. Gautrand, et al. Cerebral uptake of mefloquine enantiomers with and without the P-gp inhibitor elacridar (GF1210918) in mice. Br J Pharmacol, 2004; 141(7): p. 1214-22.

32. Seral, C., J.M. Michot, H. Chanteux, et al. Influence of P-glycoprotein inhibitors on accumulation of macrolides in J774 murine macrophages. Antimicrob Agents Chemother, 2003; 47(3): p. 1047-51.

33. Donnenberg, V.S., G.J. Burckart, B.P. Griffith, et al. $\mathrm{P}$-glycoprotein (P-gp) is upregulated in peripheral Tcell subsets from solid organ transplant recipients. J Clin Pharmacol, 2001; 41(12): p. 1271-9.

34. Chaudhary, P.M. and I.B. Roninson. Induction of multidrug resistance in human cells by transient exposure to different chemotherapeutic drugs. J Natl Cancer Inst, 1993; 85(8): p. 632-9.

35. Jancis, E.M., R. Carbone, K.J. Loechner, et al. Estradiol induction of rhodamine 123 efflux and the multidrug resistance pump in rat pituitary tumor cells. Mol Pharmacol, 1993; 43(1): p. 51-6.

36. Kota, B.P., V.H. Tran, J. Allen, et al. Characterization of PXR mediated P-glycoprotein regulation in intestinal LS174T cells. Pharmacol Res, 2010; 62(5): p. 426-31.

37. Broderick, P.J., A.B. Benjamin, and L.W. Dennis. Caffeine and psychiatric medication interactions: a review. J Okla State Med Assoc, 2005; 98(8): p. 3804.

38. Sadzuka, Y., T. Sugiyama, H. Sawanishi, et al. Enhanced efficacy of 1-methyl-3-propyl-7butylxanthine on the antitumor activity of doxorubicin against doxorubicin-resistant P388 leukemia. Cancer Lett, 1999; 138(1-2): p. 5-11.
39. Kaddoumi, A., M.N. Nakashima, M. Wada, et al. Pharmacokinetic interactions between phenylpropanolamine, caffeine and chlorpheniramine in rats. Eur J Pharm Sci, 2004; 22(2-3): p. 209-16.

40. Volm, M., T. Efferth, P. Grabner P, et al. Induction of p-glycoprotein, glutathione-s-transferase-pi, catalase, C-fos and C-erbb1 in rodent cell-lines after exposure to Doxorubicin, ethanol and caffeine. Int $\mathrm{J}$ Oncol. 1995; 6(1): p. 87-92.

41. Fernandez, F., W. Morishita, E. Zuniga, et al. Pharmacotherapy for cognitive impairment in a mouse model of Down syndrome. Nat Neurosci, 2007; 10(4): p. 411-3.

42. Liu, X., Z. Yang, J. Yang, et al. Increased Pglycoprotein expression and decreased phenobarbital distribution in the brain of pentylenetetrazole-kindled rats. Neuropharmacology, 2007; 53(5): p. 657-63.

43. Johne, A., J. Brockmoller, S. Bauer, et al. Pharmacokinetic interaction of digoxin with an herbal extract from St John's wort (Hypericum perforatum). Clin Pharmacol Ther, 1999; 66(4): p. 338-45.

44. Piscitelli, S.C., A.H. Burstein, D. Chaitt, et al. Indinavir concentrations and St John's wort. Lancet, 2000; 355(9203): p. 547-8.

45. Niemi, M., J.T. Backman, M. Neuvonen, et al. Effects of rifampin on the pharmacokinetics and pharmacodynamics of glyburide and glipizide. Clin Pharmacol Ther, 2001; 69(6): p. 400-6.

46. Westphal, K., A. Weinbrenner, M. Zschiesche, et al. Induction of P-glycoprotein by rifampin increases intestinal secretion of talinolol in human beings: a new type of drug/drug interaction. Clin Pharmacol Ther, 2000; 68(4): p. 345-55. 